\title{
4,4-Dimethyl-4-silapentane-1-ammonium trifluoroacetate (DSA), a promising universal internal standard for NMR-based metabolic profiling studies of biofluids, including blood plasma and serum
}

\author{
Mohammed F. Alum · Paul A. Shaw $\cdot$ Brian C. Sweatman · Baljit K. Ubhi · \\ John N. Haselden · Susan C. Connor
}

Received: 2 July 2007/ Accepted: 11 January 2008/Published online: 3 February 2008

(C) The Author(s) 2008

\begin{abstract}
Nuclear magnetic resonance (NMR)-based metabolic profiling of biofluids and tissues are of key interest to enhance biomarker discovery for disease, drug efficacy and toxicity studies. Urine and blood plasma/ serum are the biofluids of most interest as they are the most accessible in both clinical and preclinical studies. However, proteinaceous fluids, such as blood serum or plasma, represent the greatest technical challenge since the chemical shift $(\delta)$ and line-width $\left(v_{1 / 2}\right)$ of internal standards currently used for aqueous NMR samples are greatly affected by protein binding. We have therefore investigated the suitability of 4,4-dimethyl-4-silapentane-1-ammonium trifluoroacetate (DSA) as a universal internal standard for biofluids. Proton $\left({ }^{1} \mathrm{H}\right)$ NMR spectroscopy was used to determine the effect of serum $\mathrm{pH}(3,7.4$ and 10) and DSA concentration on the overall lineshape and position of the trimethylsilyl resonance of DSA. The results were compared to that of 3-(trimethylsilyl)propionic acid sodium salt (TSP). Both the chemical shift and line-width of the DSA peak were not significantly affected by $\mathrm{pH}$ or DSA concentration, whereas these parameters for TSP showed large variations due to protein binding. Furthermore, the peak area of DSA correlated linearly with its concentration under all $\mathrm{pH}$ conditions, whilst no linear correlation was observed with TSP. Overall, in contrast to TSP, these results support the use of DSA as an accurate universal internal chemical shift reference and concentration/normalisation standard for biofluids. In the case of
\end{abstract}

M. F. Alum (ه) · P. A. Shaw · B. C. Sweatman •

B. K. Ubhi · J. N. Haselden · S. C. Connor

Department of Investigative Preclinical Toxicology,

Safety Assessment Division, GlaxoSmithKline R \& D,

Park Road, Ware, Hertfordshire SG12 0DP, UK

e-mail: f.alum@talk21.com proteinaceous biofluids such as serum, where no current standard is available, this offers a considerable saving in both operator and spectrometer time.

\section{Keywords}

4,4-dimethyl-4-silapentane-1-ammonium trifluoroacetate (DSA) - Metabolomics · Metabonomics · Proton NMR . Blood plasma/serum · Internal reference standard

\section{Introduction}

Metabolic profiling of biofluids using proton nuclear magnetic resonance $\left({ }^{1} \mathrm{H}\right.$ NMR) spectroscopy (known as metabonomics or metabolomics) is becoming a widely used technique for disease diagnosis, toxicology and biomarker discovery (Griffin et al. 2004; Lindon et al. 2004). Urine and blood plasma/serum are the two most routinely studied biofluids due to their ease of availability and high information content. Urine has been extensively analysed since excreted products are more concentrated than in plasma or serum and provide an insight into the current disease state of an individual as well as indication of any xenobiotics taken. Analysis of plasma/serum provides information on the perturbations, and response to homeostatic control, of high, (e.g. protein) medium (e.g. lipid and peptides), and low molecular weight metabolites and inorganic solutes.

Internal chemical shift standards such as 3-(trimethylsilyl)-1-propane sulfonic acid sodium salt (DSS) and 3-(trimethylsilyl)propionic acid sodium salt (TSP) are commonly used for NMR studies in urine (Constantinou et al. 2005; Gartland et al. 1990; Lenz et al. 2004). However, due to interactions with proteins and associated NMR line-broadening, these compounds are not suitable as 
either quantitative or qualitative tools in proteinaceous solutions such as blood plasma or serum (Bell et al. 1989; Nowick et al. 2003). They are also not suitable for use in urine samples where proteinuria is observed. There is a high degree of interest in the discovery of an ideal universal internal standard for all metabolomic studies, and particularly blood plasma/serum as this is the most available biofluid across both preclinical and clinical studies. One alternative approach to minimise the lack of a suitable internal standard for plasma/serum NMR analysis has been to deproteinise the samples prior to using DSS or TSP (Daykin et al. 2002; Wevers et al. 1994). However, this involves laborious sample preparation steps and plasma/ serum metabolites of interest can be lost with the removed proteins. Other approaches include: the absolute quantification of isolated metabolite resonances through spiking known concentrations of authentic metabolite standards; and the use of formate, an endogenous compound at low concentrations $(0.3 \mathrm{mM})$, as a quantitative/normalisation standard for serum (Gérard et al. 2002; Kriat et al. 1992) since this produces an isolated sharp resonance $\left(\delta_{\mathrm{H}}=\right.$ $8.46 \mathrm{ppm})$. Both of these approaches require multiple experiments and hence reduce sample throughput. The former involves many follow-up spiking experiments and the latter requires data acquisition before and after the addition of formate to account for any endogenouslygenerated formate, thus doubling the sample handling and data acquisition times.

Desirable qualities in an NMR internal standard include: the need for high purity, chemical inertness, ease of solubility with low volatility and a singlet NMR resonance well dispersed from other analyte signals. 4,4-dimethyl-4-silapentane-1-ammonium trifluoroacetate (DSA, Fig. 1a) fits this profile and has been described previously as an internal standard for NMR studies in peptide solutions (Nowick et al. 2003). Whilst DSA has not been evaluated previously as an internal standard in biofluid samples, its low affinity for peptide binding may extend to serum proteins such as albumin and the immunoglobulins. To this end we have compared the properties of DSA and TSP with respect to NMR lineshape (width at half height $\left(v_{1 / 2}\right)$ and area) and $\mathrm{pH}$ dependence of the chemical shift $(\delta)$ in a highly proteinaceous biofluid i.e. rat serum. To aid these studies we have used partially deuterated DSA $\left(\left(\mathrm{CH}_{3}\right)_{3} \mathrm{SiCD}_{2} \mathrm{CD}_{2} \mathrm{CD}_{2} \mathrm{NH}_{3}^{+}\right.$ $\mathrm{CF}_{3} \mathrm{COO}^{-}$; Fig. 1b), leaving the trimethylsilyl group fully protonated. This simplifies the spectrum to a singlet, resonating at $\delta_{\mathrm{H}}=0.016 \mathrm{ppm}$, measured relative to TSP $\left(\delta_{\mathrm{H}}=0.000 \mathrm{ppm}\right)$ at $\mathrm{pH} 7.4$.

\section{Materials and method}

Deuterated DSA (Onyx Scientific Limited, Silverbriar, Sunderland Enterprise Park East, Sunderland, UK) and TSP (Aldrich Chemical Co., UK) were each prepared in 99.9\% $\mathrm{D}_{2} \mathrm{O}$ (Euriso-top, France) containing $\mathrm{NaN}_{3}$ (Fisher Chemicals, UK) $(1 \% \mathrm{w} / \mathrm{v}) . \mathrm{D}_{2} \mathrm{O}$ was used to dilute both solutions to achieve working concentrations of $6 \mathrm{mM}$, $5 \mathrm{mM}, 4 \mathrm{mM}, 3 \mathrm{mM}$ and $2 \mathrm{mM}$. Aliquots $(50 \mu \mathrm{l})$ of each concentration solution were transferred into separate $5 \mathrm{~mm}$ NMR tubes (Wilmad LabGlass, USA), each containing: $300 \mu \mathrm{l}$ isotonic saline $\left(10 \%(\mathrm{v} / \mathrm{v}) \mathrm{D}_{2} \mathrm{O} ; 90 \%(\mathrm{v} / \mathrm{v})\right.$ deionised $\mathrm{H}_{2} \mathrm{O} ; 0.9 \%$ (w/v) $\mathrm{NaCl}(\mathrm{BDH}$ Lab. Supplies, UK)), and $150 \mu \mathrm{l}$ control rat serum (Chemicon, USA) (previously adjusted to $\mathrm{pH} 3,7.4$ or 10 by dropwise addition of a $500 \mathrm{mM}$ hydrochloric acid or sodium hydroxide solution). The contents were thoroughly mixed by inverting the NMR tubes several times prior to NMR analysis. Samples were run immediately to minimise the impact of protein precipitation that may occur on standing at acidic $\mathrm{pH}$. All experiments were performed in triplicates.

${ }^{1} \mathrm{H}$ NMR spectroscopy was performed on all samples at a temperature of 300 Kelvin using a Bruker Avance III spectrometer operating at $699.72 \mathrm{MHz}$. One dimensional spectra were acquired using the standard Bruker pule sequence NOESYGPPR1D, which is a presaturation experiment for water suppression incorporating the first increment of the NOESY pulse sequence and a spoil gradient.

$\mathrm{RD}-90^{\circ}-\mathrm{t}_{1}-90^{\circ}-\mathrm{t}_{\mathrm{m}}-90^{\circ}-$ collect FID

The water resonance was suppressed during the $3 \mathrm{~s}$ relaxation delay (RD) and $10 \mathrm{~ms}$ mixing time. Sixty-four free induction decays (FIDs) were collected into $32 \mathrm{~K}$ data points over a $20 \mathrm{ppm}$ spectral width, which gave an acquisition time of $1.16 \mathrm{~s}$ and a total inter-scan delay of $4.16 \mathrm{~s}$. The data were Fourier transformed and zero-filled into $64 \mathrm{~K}$ data points following the application of an exponential apodisation function corresponding to a linebroadening of $0.3 \mathrm{~Hz}$. Spectra were manually phased and
Fig. 1 Chemical structure of (a) DSA and (b) deuterated DSA

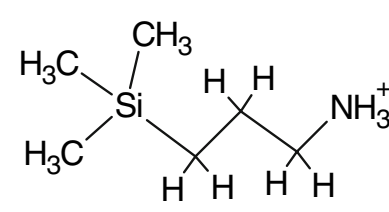

(a)

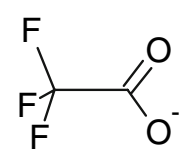<smiles>[2H]C([2H])([NH3+])C([2H])([2H])C([2H])([2H])[Si](C)(C)C</smiles>

(b) 
base-line corrected using proprietary software (Topspin Version 1.3, Bruker Biospin, Karlsruhe, Germany). The chemical shifts were internally referenced to the $\alpha$-glucose anomeric proton doublet resonance at $5.24 \mathrm{ppm}$. Peak areas of DSA, TSP and lactate quartet $\left(\delta_{\mathrm{H}}=4.14 \mathrm{ppm}\right)$ were integrated within a region of $\pm 0.05 \mathrm{ppm}$ from the centre of each peak, and in turn the area under each DSA and TSP peak was calculated with respect to that of the lactate peak area. The line-width measurements $\left(v_{1 / 2}\right)$ were also recorded for each spectrum following Fourier transformation in the absence of the apodisation function.

\section{Results and discussion}

Water-soluble ${ }^{1} \mathrm{H}$ NMR internal standards, DSS and TSP have been reported to interact with proteins and other macromolecules causing their resonances to broaden and shift (Bell et al. 1989; Kriat et al. 1992; Lam and Kotowycz 1977; Live and Chan 1973; Nowick et al. 2003; Shimizu et al. 1994). In addition, the chemical shift of TSP has been shown to vary with pH (De Marco 1977), temperature (Farrant et al. 1994; Wishart et al. 1995) and protein concentration (Shimizu et al. 1994). Consequently, although both compounds are frequently used for NMR analysis of urine, tissue extract (Constantinou et al. 2005; Le Belle et al. 2002; Lenz et al. 2004) and potentially deproteinised serum extract, neither compound is ideal as an internal standard for biofluids containing high levels of macromolecules.

To eliminate these shortcomings Nowick et al. (2003) synthesised and evaluated DSA as an internal standard for use in peptide solutions. They found the chemical shift of the trimethylsilyl resonance in the ${ }^{1} \mathrm{H}$ NMR spectrum to be insensitive to $\mathrm{pH}$, temperature and concentration of several cationic peptides. The present study builds upon this preliminary work and investigates its utility in proteinaceous biofluids. We have compared deuterated DSA and TSP as chemical shift and normalisation standards in rat serum using a range of $\mathrm{pHs}$ above and below the pKa of TSP (pH 5) and close to the estimated pKa of DSA (predicted pH 8-10).

To obtain accurate chemical shift and line-width measurements for DSA and TSP, it was necessary to reference all NMR spectra to the chemical shift of a compound that itself remains unaffected by $\mathrm{pH}$ and protein interaction. Glucose was chosen for this purpose as it is an endogenous compound, present in rat serum at readily detectable levels, with no ionisable groups and does not interact with serum macromolecules (Farrant et al. 1994). It is rarely used as an internal standard since it produces several multiplet, overlapping NMR resonances, although the anomeric protons $\left(\delta_{\mathrm{H}}=5.24\right.$ and $\left.4.65 \mathrm{ppm}\right)$ are clearly resolved. In addition, the anomeric proton chemical shifts are insensitive to $\mathrm{pH}$ and temperature change (Farrant et al. 1994; Lutz et al. 1993). Therefore all spectra were referenced to the ${ }^{1} \mathrm{H}$ resonance of the $\alpha$-glucose anomeric proton doublet at $5.24 \mathrm{ppm}$ as it was furthest from the offset of the water irradiation frequency. The peak width at half height $\left(v_{1 / 2}\right)$ was calculated from the ${ }^{1} \mathrm{H}$ resonance of the $\beta$-glucose anomeric proton because the individual lines of the doublet resonance were more clearly resolved than those of the $\alpha$ anomer due to a larger coupling constant. The lactate quartet $\left(\delta_{\mathrm{H}}=4.14 \mathrm{ppm}\right)$ was chosen in preference to the glucose anomers for peak area normalisation because it had less peak overlap with underlying lipid resonances and was further from the water irradiation offset and therefore more suitable for quantitation. Although lactate was reported to interact with proteins (Chatham and Forder 1999), we have observed the lactate quartet to $\alpha$-glucose anomeric proton doublet and also alanine methyl doublet ratio to be constant in all DSA and TSP concentrations and pHs tested, and therefore it was inferred that the proportion of unbound lactate to bound was consistent throughout the experiment.

The standard curves in Fig. 2 relating the peak area to concentration of DSA and TSP at the three pHs illustrates DSA to be correlated linearly with its concentration at the $\mathrm{pH}$ conditions tested. The peak area is directly proportional
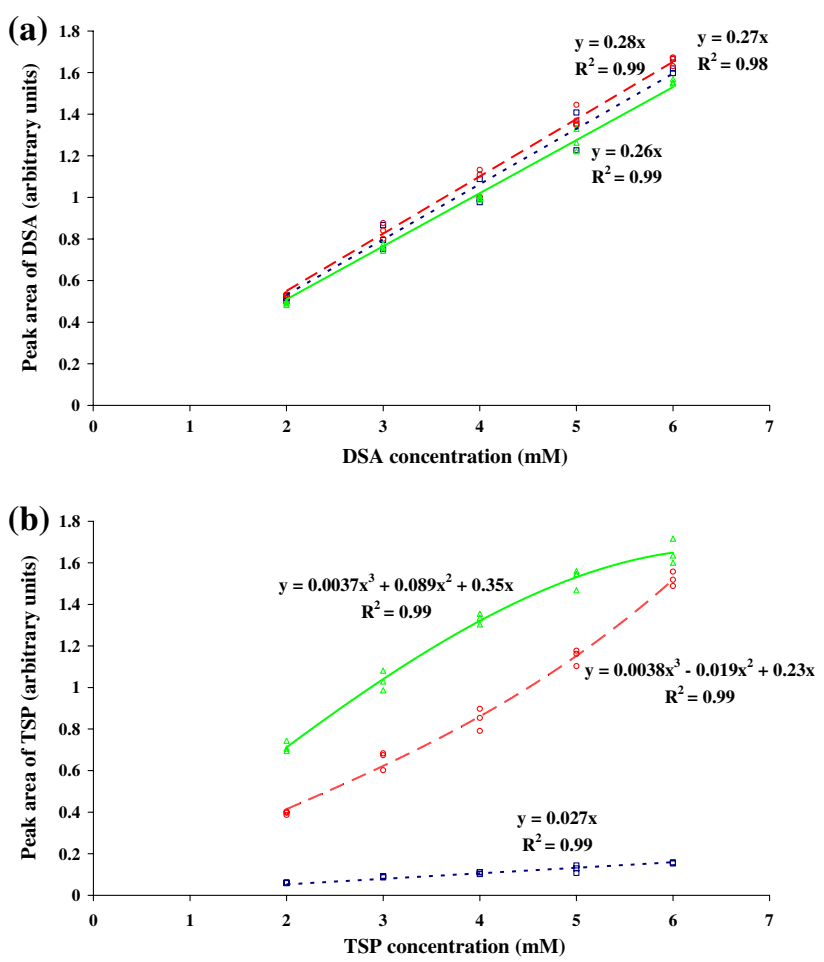

Fig. 2 Standard curves relating peak area to concentration for the trimethylsilyl resonance of (a) DSA and (b) TSP at pH 3 ( $\square$ ), $7.4(\bigcirc)$ and $10(\Delta)$ in control rat serum. Areas were calculated by integrating a region of $\pm 0.05 \mathrm{ppm}$ from the centre of the DSA, TSP and lactate quartet resonances and then normalising the lactate area to obtain arbitrary area values for DSA and TSP 
to the concentration, thus a doubling of DSA concentration corresponded to a doubling of its peak area. This suggests that the DSA resonance intensity is not being attenuated by interaction with serum components thus demonstrating its suitability as a quantitative or normalisation standard for serum NMR studies. Conversely, as previously shown (Kriat et al. 1992), the TSP peak area at pHs 7.4 and 10 did not correlate linearly with, and were not proportional to, their concentration (Fig. 2b). The TSP peak at $\mathrm{pH} 3$ remained almost undetectable at all concentrations tested and, whilst appearing to be almost linear, would be unusable for referencing or quantitation. These effects are probably due to interaction with serum components such as proteins (Bell et al. 1989; Kriat et al. 1992; Shimizu et al. 1994), where the greatest binding was observed at $\mathrm{pH} 3$.

DSA concentration had no observable effect on either the $v_{1 / 2}(\sim 2 \mathrm{~Hz})$ (Table 1) or chemical shift of the DSA peak at $\mathrm{pH} 3$ (Fig. 3a), suggesting minimal interaction with proteins (or other serum components) under acidic conditions. At $\mathrm{pH} 7.4$ and to a greater extend at $\mathrm{pH} 10$, the DSA peak shifted and broadened relative to $\mathrm{pH} 3$. These effects are minimal, particularly at $\mathrm{pH} 7.4$ and probably arises from a slight interaction of DSA with serum components (e.g. proteins) rather than $\mathrm{pH}$ since Norwick et al. (2003) previously demonstrated that the DSA resonance was unaffected by $\mathrm{pH}$ in standard solutions. A slight downfield shift was also observed with increasing concentrations of DSA at $\mathrm{pH} 10$ but not $\mathrm{pH} 3$ or $\mathrm{pH}$ 7.4. These effects probably arise from protein binding of the uncharged DSA molecules at the higher $\mathrm{pHs}$ (predicted $\mathrm{pKa}$ at $\mathrm{pH}$ 8-10). However, the protein interactions at $\mathrm{pH} 7.4$ are not severe enough to preclude its use as a quantitative or normalisation standard and chemical shift reference. This strengthens the position of DSA as an accurate internal standard at physiological $\mathrm{pH}$.

In contrast, the chemical shift of TSP was sensitive to both $\mathrm{pH}$ and concentration variations (Fig. 3b). This effect was more evident at $\mathrm{pH} \mathrm{3}$, with severe peak broadening resulting in an undefined TSP peak (Fig. 2b). This suggests that TSP was undergoing chemical exchange processes at an intermediate rate relative to the NMR timescale. As this phenomenon is not observed in standard solutions, and as previous literature has suggested, chemical exchange processes are probably involving exchange between the protein-bound and unbound forms (Bell et al. 1989; Kriat et al. 1992; Shimizu et al. 1994). More defined and intense TSP resonances were observed at $\mathrm{pH} 10$ and to a slightly lesser extend at $\mathrm{pH} 7.4$, although still significantly broader than those of glucose and DSA at $\mathrm{pH} 3$ and 7.4. This indicates that the affinity of TSP for protein increases with decreasing $\mathrm{pH}$, hence the reverse of the $\mathrm{pH}$ effects observed with DSA, which is not unexpected when comparing an acid with an amine if it is inferred that binding is predominantly in the uncharged state. Comparative pKas for DSA and TSP are 8-10 (predicted) and 5 (De Marco 1977) respectively. It is also possible that, as previously reported by Shimizu et al. (1994), the conformations of several proteins unfold to the molten globule (MG) state under acidic conditions and proteins such as albumin in this state may have a greater affinity for TSP through hydrophobic interactions.

Comparison of the shift and linewidth of the TSP peaks at $\mathrm{pH} 7.4$ and $\mathrm{pH} 10$ indicates that there is a downfield shift and reduction in linewidth with increasing concentrations of TSP (Table 1, Fig. 3b). This may be due to saturation of the binding sites on the protein and consequential increase in the proportion of unbound to bound TSP molecules. However, greater attenuation and a larger shift of the TSP resonance were observed at $\mathrm{pH} 3$ which were unaffected by increasing TSP concentration, suggesting that at lower $\mathrm{pH}$ (i.e. below the $\mathrm{pKa}$ ) no saturation of binding occurred.

Line-width values at half height $\left(v_{1 / 2}\right)$ (Table 1$)$ further corroborate our proposal that DSA is a suitable universal internal standard for NMR-based metabolomic studies due to minimal macromolecular interactions and $\mathrm{pH}$ effects in contrast to TSP. Metabolites that do not interact with protein should produce peaks that have similar values for $v_{1 / 2}$. To examine and account for sample-to-sample variations in field homogeneity, the $v_{1 / 2}$ of the DSA and TSP resonances at each concentration and $\mathrm{pH}$ were normalised to the mean $v_{1 / 2}$ of the non protein-bound $\beta$-glucose doublet. At all concentrations the $v_{1 / 2}$ of DSA at $\mathrm{pH} 3$ was
Table 1 Mean $v_{1 / 2} *$ of the triplicate DSA and TSP peaks normalised to the mean $v_{1 / 2}$ of triplicate $\beta$-glucose doublet at different concentrations and $\mathrm{pH}$ values

* Determined using proprietary software

\begin{tabular}{|c|c|c|c|c|c|c|}
\hline \multirow[t]{3}{*}{ Concentration $(\mathrm{mM})$} & \multicolumn{6}{|c|}{ Mean $v_{1 / 2}$ internal standard/Mean $v_{1 / 2} \beta$-glucose $(\mathrm{Hz})$} \\
\hline & \multicolumn{2}{|l|}{$\mathrm{pH} 3$} & \multicolumn{2}{|c|}{$\mathrm{pH} 7.4$} & \multicolumn{2}{|c|}{$\mathrm{pH} 10$} \\
\hline & DSA & TSP & DSA & TSP & DSA & TSP \\
\hline 2 & 1.10 & 15.73 & 2.13 & 7.16 & 3.15 & 3.59 \\
\hline 3 & 1.11 & 14.86 & 2.27 & 6.76 & 3.04 & 3.29 \\
\hline 4 & 1.08 & 14.42 & 2.27 & 5.72 & 2.74 & 3.20 \\
\hline 5 & 1.10 & 16.55 & 2.03 & 4.72 & 3.12 & 3.01 \\
\hline 6 & 1.08 & 15.25 & 1.83 & 3.98 & 2.89 & 2.98 \\
\hline
\end{tabular}


Fig. 3 Stacked ${ }^{1} \mathrm{H}$ NMR spectra of the trimethylsilyl resonance of (a) DSA and (b) TSP in control rat serum at $\mathrm{pH} 3$ (bottom), 7.4 (middle) and 10 (top), overlaid with increasing concentrations of the two internal standards. Spectra were normalised to the lactate quartet resonance at $4.14 \mathrm{ppm}$ and referenced to the $\alpha$-glucose resonance at $5.24 \mathrm{ppm}$. Due to the relative scaling, TSP peaks at $\mathrm{pH} 3$ do not appear in this figure, however, the broad peaks are observed when magnified (a)

(b)
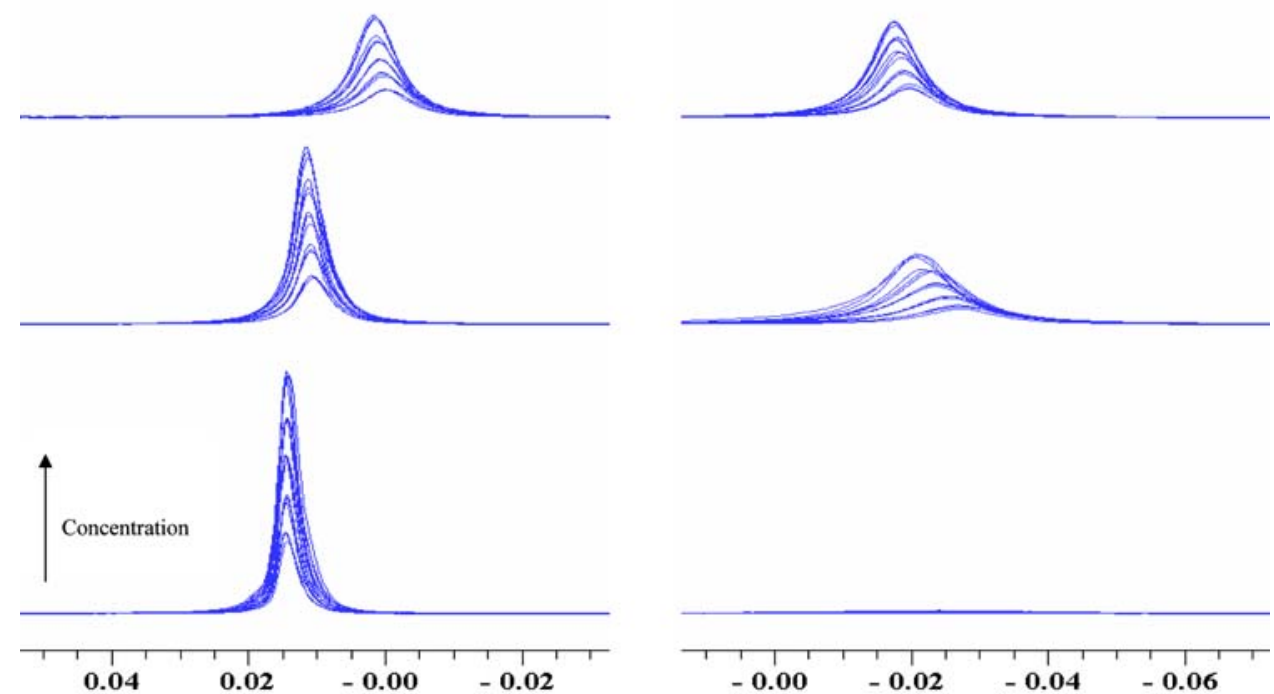

Chemical Shift (ppm)

identical, within experimental error, to that of the $\beta$-glucose, and at $\mathrm{pH} 7.4$ and 10 the $v_{1 / 2}$ of DSA was twice and three times that of glucose respectively (Table 1 ). In contrast, significant decreases were observed in the $v_{1 / 2}$ of TSP with increasing concentrations, particular at $\mathrm{pH} 7.4$ (Table 1). However at $\mathrm{pH} 3$, the resonance intensities were very low and the $v_{1 / 2}$ at each concentration was estimated to be at least 15 -fold larger than that of the $\beta$-glucose.

\section{Conclusion}

Blood plasma or serum is often the most available biofluid in both the preclinical and clinical setting and is therefore of key interest in metabolic profiling studies. However, historically there has been no suitable internal standard that can act as a reference for both chemical shift and quantification since the advent of biofluid NMR studies. Partial solutions for data normalisation, using addition of known concentrations of formate or other metabolite standards have been developed, but additional sample manipulation and experimentation is required to allow for the endogenous concentrations of the spiked compounds. This therefore doubles the amount of NMR spectrometer time required per sample. An alternative approach includes crude normalisation by total area to allow comparison across spectra, but neither of these approaches is ideal.

In this work we propose DSA as both an internal chemical shift reference and concentration/normalisation standard for all NMR-based metabolic profiling studies. It fulfils all the necessary criteria, i.e. it gives rise to a singlet resonance in a clear region of the spectrum that is relatively unaffected by $\mathrm{pH}$ and macromolecular interactions on the NMR timescale studied (i.e. $700 \mathrm{MHz}$ ). It should therefore be considered as a universal internal standard for future biofluid NMR studies, even in proteinaceous solutions.

Acknowledgments The authors wish to thank James S. Nowick, (Department of Chemistry, University of California, Irvine, California) for the initial supply of undeuterated DSA.

Open Access This article is distributed under the terms of the Creative Commons Attribution Noncommercial License which permits any noncommercial use, distribution, and reproduction in any medium, provided the original author(s) and source are credited.

\section{References}

Bell, J. D., Brown, J. C. C., \& Sadler, P. J. (1989). NMR studies of body fluids. NMR in Biomedicine, 2, 246-256.

Chatman, J. C., \& Forder, J. R. (1999). Lactic acid and protein interactions: Implications for the NMR visibility of lactate in biological systems. Biochimica et Biophysica Acta, 1426, 177-184.

Constantinou, M. A., Papakonstantinou, E., Spraul, M., et al. (2005). ${ }^{1} \mathrm{H}$ NMR-based metabonomics for the diagnosis of inborn errors of metabolism in urine. Analytica Chimica Acta, 542, 169-177.

Daykin, C. A., Foxall, P. J. D., Connor, S. C., Lindon, J. C., \& Nicholson, J. K. (2002). The comparison of plasma deproteinization methods for the detection of low-molecular-weight metabolites by ${ }^{1} \mathrm{H}$ nuclear magnetic resonance spectroscopy. Analytical Biochemistry, 304, 220-230.

De Marco, A. (1977). pH dependence of internal references. Journal of Magnetic Resonance, 26, 527-528.

Farrant, R. D., Lindon, J. C., \& Nicholson, J. K. (1994). Internal temperature calibration for ${ }^{1} \mathrm{H}$ NMR spectroscopy studies of blood plasma and other biofluids. NMR in Biomedicine, 7, 243-247. 
Gartland, K. P. R., Sanins, S. M., Nicholson, J. K., Sweatman, B. C., Beddell, C. R., \& Lindon, J. C. (1990). Pattern recognition analysis of high resolution ${ }^{1} \mathrm{H}$ NMR spectra of urine. A nonlinear mapping approach to the classification of toxicological data. NMR in Biomedicine, 3, 166-172.

Gérard, N., Loiseau, S., Duchamp, G., \& Seguin, F. (2002). Analysis of the variations of follicular fluid composition during follicular growth and maturation in the mare using proton nuclear magnetic resonance ( ${ }^{1} \mathrm{H}$ NMR). Reproduction, 124, 241-248.

Griffin, J. L., \& Bollard M. E. (2004). Metabolomics: Its potential as a tool in toxicology for safety assessment and data integration. Current Drug Metabolism, 5, 389-398.

Krait, M., Confort-Gouny. S., Vion-Dury, J., Sciaky, M., Viout, P., \& Cozzone, P. J. (1992). Quantitation of metabolites in human blood serum by proton magnetic resonance spectroscopy. A comparative study of the use of formate and TSP as concentration standards. NMR in Biomedicine, 5, 179-184.

Lam, Y. F., \& Kotowycz, G. (1977). Caution concerning the use of sodium 2,2-demethyl-2-silapentane-5-sulfonate (DSS) as a reference for proton NMR chemical shift studies. FEBS Letters, 78, $181-183$

Le Belle, J. E., Harris, N. G., Williams, S. R., \& Bhakoo, K. K. (2002). A comparison of cell and tissue extraction techniques using high-resolution ${ }^{1} \mathrm{H}$ NMR spectroscopy. NMR in Biomedicine, 15, 37-44.

Lenz, E. M., Bright, J., Knight, R., Wilson, I. D., \& Major, H. (2004). Cyclosporin A-induced changes in endogenous metabolites in rat urine: A metabonomic investigation using high field ${ }^{1} \mathrm{H}$ NMR spectroscopy, HPLC-TOF/MS and chemometrics. Journal of Pharmaceutical and Biomedical Analysis, 35, 599-608.

Lindon, J. C., Holmes E., Bollard M. E., Stanley E. G., \& Nicholson J. K. (2004). Metabolomics technologies and their applications in physiological monitoring, drug safety assessment and disease diagnosis. Biomarkers, 9, 1-31.

Live, D. H., \& Chan, S. I. (1973). The use of DSS as an internal standard in PMR studies of nucleic acid interactions. Organic Magnetic Resonance, 5, 275-276.

Lutz, N. W., Kuesel, A. C., \& Hull, W. E. (1993). A ${ }^{1}$ H-NMR method for determining temperature in cell culture perfusion systems. Magnetic Resonance in Medicine, 29, 113-118.

Nowick, J. S., Khakshoor, O., Hashemzadeh, M., \& Brower, J. O. (2003). DSA: A new internal standard for NMR studies in aqueous solution. Organic Letters, 5, 3511-3513.

Shimizu, A., Ikeguchi, M., \& Sugai, S. (1994). Appropriateness of DSS and TSP as internal references for ${ }^{1} \mathrm{H}$ NMR studies of molten globule proteins in aqueous media. Journao of Biomolecular NMR, 4, 859-862.

Wevers, R. A., Engelke, U., \& Heerschap, A. (1994). High-resolution ${ }^{1}$ H-NMR spectroscopy of blood plasma for metabolic studies. Clinical Chemistry, 40, 1245-1250.

Wishart, D. S., Bigam, C. G., Yao, J., et al. (1995). ${ }^{1} \mathrm{H},{ }^{13} \mathrm{C}$ and ${ }^{15} \mathrm{~N}$ chemical shift referencing in biomolecular NMR. Journal of Biomolecular NMR, 6, 135-140. 